\title{
Auranofin-mediated inhibition of PI3K/AKT/mTOR axis and anticancer activity in non-small cell lung cancer cells
}

\author{
Hongyu $\mathrm{Li}^{1,4}$, Jing Hu${ }^{1}$, Shuhong Wu${ }^{1}$, Li Wang ${ }^{1}$, Xiaobo Cao ${ }^{1}$, Xiaoshan Zhang ${ }^{1}$, \\ Bingbing Dai ${ }^{1}$, Mengru Cao ${ }^{1}$, Ruping Shao ${ }^{1}$, Ran Zhang ${ }^{1}$, Mourad Majidi ${ }^{1}$, Lin $\mathrm{Ji}^{1}$, \\ John V. Heymach ${ }^{2}$, Michael Wang ${ }^{3}$, Shiyang Pan ${ }^{5}$, John Minna ${ }^{6}$, Reza J. Mehran ${ }^{1}$, \\ Stephen G. Swisher ${ }^{1}$, Jack A. Roth ${ }^{1}$, and Bingliang Fang ${ }^{1}$ \\ ${ }^{1}$ Department of Thoracic and Cardiovascular Surgery, University of Texas MD Anderson Cancer Center, Houston, Texas, USA \\ ${ }^{2}$ Department of Thoracic/Head \& Neck Medical Oncology, University of Texas MD Anderson Cancer Center, Houston, Texas, USA \\ ${ }^{3}$ Department of Lymphoma, University of Texas MD Anderson Cancer Center, Houston, Texas, USA \\ ${ }^{4}$ Jilin Province Cancer Hospital, Changchun, Jilin, China \\ ${ }^{5}$ Department of Laboratory Medicine, The First Affiliated Hospital of Nanjing Medical University, Nanjing, Jiangsu, China \\ ${ }^{6}$ Hamon Center for Therapeutic Oncology, The Harold C. Simmons Comprehensive Cancer Center, University of Texas \\ Southwestern Medical Center, Dallas, Texas, USA
}

Correspondence to: Bingliang Fang, e-mail: bfang@mdanderson.org

Keywords: lung cancer, drug repurposing, anticancer agent, biomarkers

Received: August 19, $2015 \quad$ Accepted: November 21, 2015

Published: December 09, 2015

\section{ABSTRACT}

\begin{abstract}
Auranofin, a gold complex that has been used to treat rheumatoid arthritis in clinics and has documented pharmacokinetic and safety profiles in humans, has recently been investigated for its anticancer activity in leukemia and some solid cancers. However, auranofin's single agent activity in lung cancer is not well characterized. To determine whether auranofin has single agent activity in lung cancer, we evaluated auranofin's activity in a panel of 10 non-small cell lung cancer (NSCLC) cell lines. Cell viability analysis revealed that auranofin induced growth inhibition in a subset of NSCLC cell lines with a half maximal inhibitory concentration $\left(\mathrm{IC}_{50}\right)$ below $1.0 \mu \mathrm{M}$. Treatment with auranofin elicited apoptosis and necroptosis in auranofin-sensitive cell lines. Moreover, the susceptibility of NSCLC cells to auranofin was inversely correlated with TXNRD1 expression in the cells. Transient transfection of the TXNRD1-expressing plasmid in auranofin-sensitive Calu3 cells resulted in partial resistance, indicating that high TXNRD level is one of causal factors for resistance to auranofin. Further mechanistic characterization with proteomic analysis revealed that auranofin inhibits expression and/or phosphorylation of multiple key nodes in the PI3K/AKT/mTOR pathway, including S6, 4EBP1, Rictor, p70S6K, mTOR, TSC2, AKT and GSK3. Ectopic expression of TXNRD1 partially reversed auranofin-mediated PI3K/ AKT/mTOR inhibition, suggesting that TXNRD1 may participate in the regulation of PI3K/AKT/mTOR pathway. Administration of auranofin to mice with xenograft tumors derived from NSCLC cells significantly suppressed tumor growth without inducing obvious toxic effects. Our results demonstrated feasibility of repurposing auranofin for treatment of lung cancer.
\end{abstract}

\section{INTRODUCTION}

Lung cancer is one of the top 2 leading causes of death in the United States and other developed countries [1]. Globally, lung cancer's annual incidence is approximately 1.8 million, with an annual mortality of approximately 1.6 million [2]. The 5-year overall survival rate for lung cancer patients has improved only moderately over the past 4 decades despite the use of many therapeutic modalities [3]. Therefore, development of new therapeutic strategies for this deadly disease is urgently needed. However, anticancer drug development 
is impeded by high failure rates, primarily because of lack of efficacy, inability to identify responders, and intolerable toxic effects [4]. Safety concerns are one of the major causes of discontinuation of drug development preclinically and clinically and discontinuation of a drug after FDA approval $[5,6]$. Thus, substantial efforts have been devoted to repurposing FDA-approved drugs with known safety in humans for new indications [7-10]. Indeed, thalidomide has been successfully repurposed for the treatment of multiple myeloma [7]. Our recent finding that ibrutinib, a drug approved for the treatment of B cell malignancy, has effective anti-EGFR activity in erlotinibresistant lung cancer [9] has quickly translated to a clinical trial, demonstrating that drug repurposing can have a rapid impact on cancer therapy.

Using a genome-wide synthetic lethality screen of a small interfering RNA (siRNA) library, we recently found that thioredoxin reductases 1 (TXNRD1) is a synthetic lethal partner of AKT in non-small cell lung cancer (NSCLC) cells [11]. Inhibiting TXNRD activity with siRNA or the small-molecule inhibitor auranofin dramatically sensitized NSCLC cells to treatment with the AKT inhibitor MK2206 [11]. Auranofin (Ridaura) is a gold complex that has been used by physicians to treat rheumatoid arthritis since the 1980s [12], and it has documented pharmacokinetic and safety profiles in humans [13-15]. Long-term use of auranofin is well tolerated in both juvenile and elderly patients [13-15]. The common side effects are loose stools or diarrhea, skin rash, stomatitis or conjunctivitis, and proteinuria $[14,16]$. The dropout rate due to adverse events in the treatment group was lower than in the placebo group in clinical trials [15], demonstrating that auranofin has an excellent safety profile. Recent studies have demonstrated that auranofin is highly effective against Entamoeba histolytica infection, leading to a quick FDA approval for the treatment of amebiasis with auranofin [17]. The use of auranofin to treat various cancers has also been explored [18-20], and auranofin is currently in clinical trials for the treatment of leukemia [21]. A recent study on the effects of auranofin in chronic lymphocytic leukemia revealed that auranofin overcame apoptosis resistance mediated by protective stromal cells [22], suggesting that auranofin may target the tumor microenvironment as well. Moreover, patients with rheumatoid arthritis treated with gold had lower malignancy rates than those not treated with gold [23], further supporting the feasibility of using auranofin for cancer therapy. To further explore the possibility of using auranofin for treatment of lung cancer, we determined single agent activity of auranofin in a panel of lung cancer cell lines. Here we report auranofin's anticancer activity in non-small cell lung cancer cell lines in vitro and vivo. Our results revealed that auranofin inhibit $\mathrm{PI} 3 \mathrm{~K} / \mathrm{AKT} / \mathrm{mTOR}$ axis and induce potent anticancer activity in a subset of lung cancer cell lines.

\section{RESULTS}

\section{Auranofin-mediated anti-lung cancer activity in vitro}

Our recent study revealed that TXNRD1 siRNA and its inhibitor auranofin were synthetically lethal with the novel AKT inhibitor MK2206 in lung cancer cells and dramatically enhanced the efficacy of MK2206 in both in vitro and in vivo models [11]. To further investigate the potential application of auranofin for lung cancer therapy, we determined the single-agent activity of auranofin in 10 NSCLC cell lines. The cells were treated with different concentrations of auranofin ranging from $62.5 \mathrm{nM}$ to $2 \mu \mathrm{M}$. Dose-dependent cell viability was determined using the sulforhodamine B assay, as described previously [9, 24]. Results showed that NSCLC cells had differential sensitivity to auranofin (Figure 1). Six of the 10 cell lines tested had a half maximal inhibitory concentration $\left(\mathrm{IC}_{50}\right)$ below 1.0
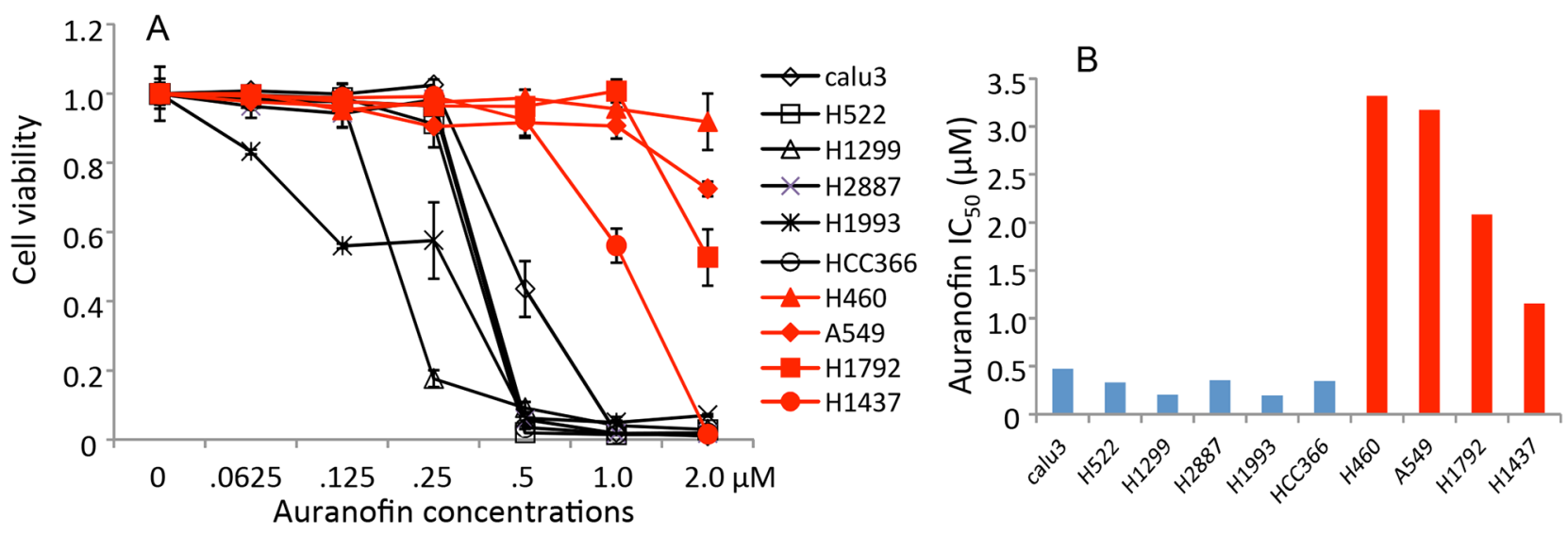

Figure 1. In vitro activity of auranofin in NSCLC cells. A. Dose-response of auranofin in 10 NSCLC cell lines determined by cell viability assays. The values in control cells were set as 1 . Data are presented as mean \pm standard deviation (SD) of a quadruplet assay. B. Auranofin $\mathrm{IC}_{50}$ values $(\mu \mathrm{M})$ determined by cell viability assays. 
$\mu \mathrm{M}$ and 3 cell lines had an $\mathrm{IC}_{50}$ above $2 \mu \mathrm{M}$, the highest concentration tested. $\mathrm{H} 1437$ had intermediate sensitivity $\left(\mathrm{IC}_{50}=1.1 \mu \mathrm{M}\right)$. This result strongly suggested that auranofin may have single agent activity in some NSCLC cells.

\section{Auranofin induces robust cell death in sensitive lung cancer cells}

We sought to determine whether auranofin triggers cytostatic or cytotoxic effects in lung cancer cells. Lung cancer cell lines Calu3, HCC366, and A549 were treated with $0.5 \mu \mathrm{M}$ auranofin for $12-48$ hours. Cells treated with DMSO served as a control. Apoptosis was measured by fluorescence-activated cell sorting after staining with annexin $\mathrm{V}$ and propidium iodide. Results showed that treatment with $0.5 \mu \mathrm{M}$ auranofin for 24-48 hours induced robust cell death or apoptosis in Calu3 and HCC366 cells. Only background cell death was detected in A549 cells at all time points tested, whereas in Calu3 and HCC366 cells, background cell death was detected at the early time point (12 hours) and robust cell death was detected thereafter (Figure 2A). Western blot analysis of cell lysates harvested at 24 hours also demonstrated a dramatic increase in cleaved PARP levels in HCC366 and Calu3 cells, but not in A549 cells (Figure 2B), suggesting that apoptosis is one of the mechanisms of auranofin-induced cell death in auranofinsensitive lung cancer cells. LC3 II was mildly increased in HCC366 and Calu3 cells after treatment with $0.5 \mu \mathrm{M}$ auranofin for 24 hours, suggesting the presence of some autophagy in auranofin-treated cells. We also investigated whether programmed necrotic cell death or necroptosis [25] is involved in auranofin induced cell killing by Western blot analysis on phosphorylation of mixed lineage kinase domain-like protein (MLKL), a hallmark of necroptosis $[25,26]$. The result showed that treatment of HCC366 and Calu3 cells with $0.5 \mu \mathrm{M}$ auranofin induced time-dependent elevation of phospho-MLKL (Figure 2C). These results demonstrated that auranofin-induced cytotoxicity may be caused by multiple programmed cell death mechanisms. .

\section{TXNRD1 expression is inversely associated with auranofin-mediated anti-lung cancer activity}

Because of high affinity of auranofin to thiols, TXNRD, the only enzymes that catalyze the reduction of thioredoxin (TXN) with electrons from NADPH [27, 28], have been identified the major targets of the goldcontaining drugs such as auronofin $[19,29]$. To determine

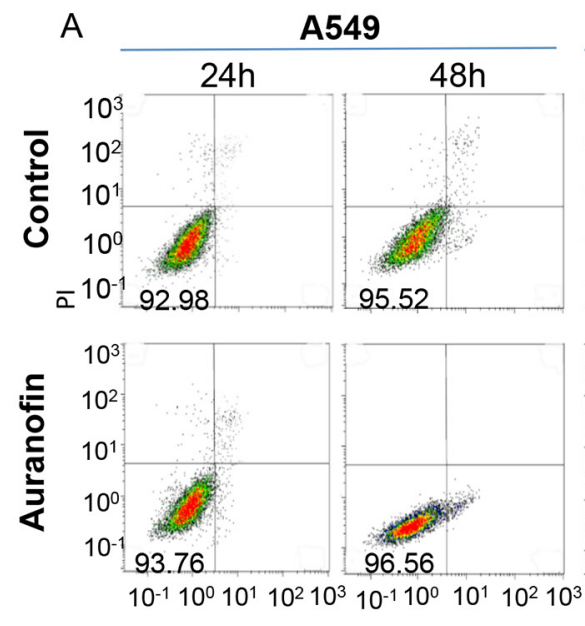

B

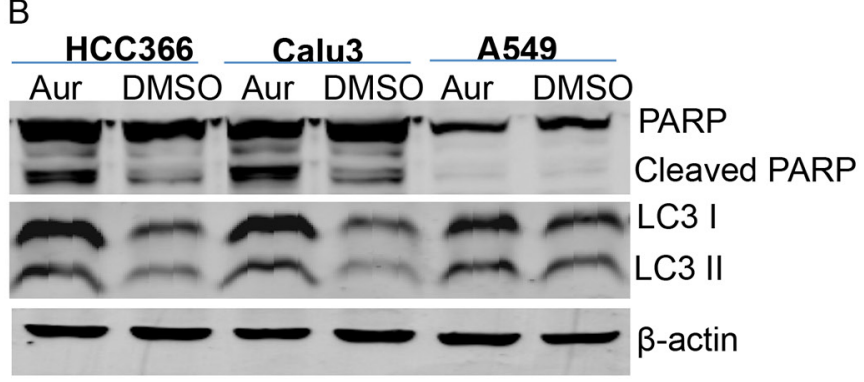

Calu3
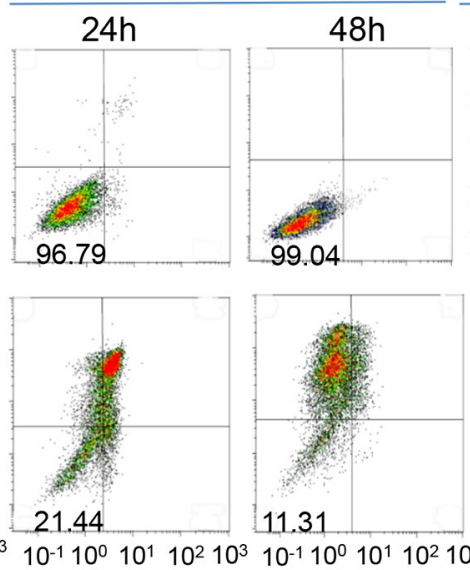

$0^{-1} 10^{0} 10^{1} 10^{2} 10^{3} 10^{-1} 10^{0} 10^{1} 10^{2} 10^{3} 10^{-1} 10^{0} 10^{1} 10^{2} 10^{3}$ 60.97

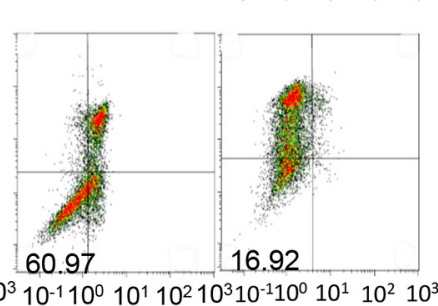

C

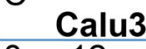

$\begin{array}{llll}0 & 12 & 24 & 48\end{array}$

HCC366
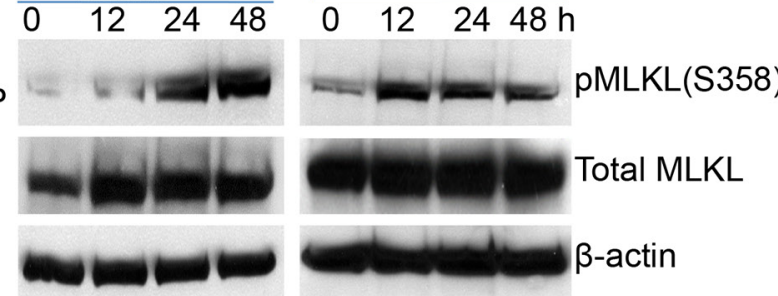

Figure 2. Auranofin-induced cytotoxicity in NSCLC cells. A. Auranofin-sensitive Calu3 and HCC366 cells and auranofin-resistant A549 cells were treated with $0.5 \mu \mathrm{M}$ auranofin or DMSO for 24 or $48 \mathrm{~h}$. Cell death was determined by fluorescence-activated cell sorting after staining with annexin $\mathrm{V}$ and propidium iodide. The numbers in the lower left box of each graph represent the number of surviving cells. B. Western blot analysis of PARP and LC3 levels after treatment with $0.5 \mu \mathrm{M}$ auranofin for 24 hours. $\beta$-actin is used as a loading control. C. Western blot analysis on phosphorylation of MLKL in Calu3 and HCC366 after treatment with $0.5 \mu \mathrm{M}$ auranofin for different time as indicated. $\beta$-actin is used as a loading control. 
whether auranofin's activity is associated with endogenous TXNRD1 expressions, we analyzed the TXNRD1 levels in NSCLC cell lines used in this study. Western blot analysis revealed that lung cancer cells that were highly sensitive to auranofin all expressed low levels of TXNRD1, whereas lung cancer cells with high TXNRD1 levels were relatively resistant to auranofin (Figure 3A). Enzymatic analysis revealed that cell lines with high TXNRD1 protein levels also had high TXNRD1 enzymatic activity. Correlation analysis revealed that auranofin $\mathrm{IC}_{50}$ values were significantly correlated with TXNRD enzymatic activity levels in lung cancer cell lines $(r=0.78, P=$ 0.007), demonstrating that endogenous TXNRD1 levels in tumor cells are inversely associated with auranofin's activity (Figure 3B, 3C). This results indicate that TXNRD1 expression in tumor cells may be used as a predictive biomarker to identify those most likely to respond to auranofin.

To further determine whether intracellular TXNRD1 is causally associated with the resistance to auranofin's anticancer activity in NSCLC cells, we transfected Calu3 cells with a plasmid expressing TXNRD1 or the control plasmid pcDNA3. Cells were treated with auranofin at $24 \mathrm{~h}$ after the transfection. Cell viability was then determined at $72 \mathrm{~h}$ after auranofin treatment. The result showed that transient transfection of the TXNRD1 expressing plasmid rendered cells partially resistant to auranofin (Figure 3D, 3E), suggesting that high level of TXNRD1 is one of causal factors of resistance to auranofin in NSCLC cells.

\section{Auranofin inhibits multiple key nodes in the PI3K/AKT/mTOR pathway}

To determine the mechanisms of auranofin-mediated anti-lung cancer activity, we analyzed the auranofininduced changes in proteins and protein phosphorylation in Calu3 and HCC366 cells using RPPA, as we previously reported $[30,31]$. Cell lysates were harvested after being treated with DMSO or $0.5 \mu \mathrm{M}$ auranofin for $0.5,1,3,8$, or 24 hours and subjected to RPPA analysis of 214 proteins or protein phosphorylation using validated antibodies available in our Proteomic Core facility. Results showed that treatment with auranofin led to drastic time-dependent suppression of several key nodes in the PI3K/AKT/mTOR pathway and in the protein translation machinery in both Calu3 and HCC366 cells, including S6, 4EBP1, Rictor, p70S6K, mTOR, TSC, AKT, and GSK3, indicating that auranofin may target multiple key nodes in the PI3K/AKT/ mTOR axis (Figure 4). Most of those inhibitions occurred
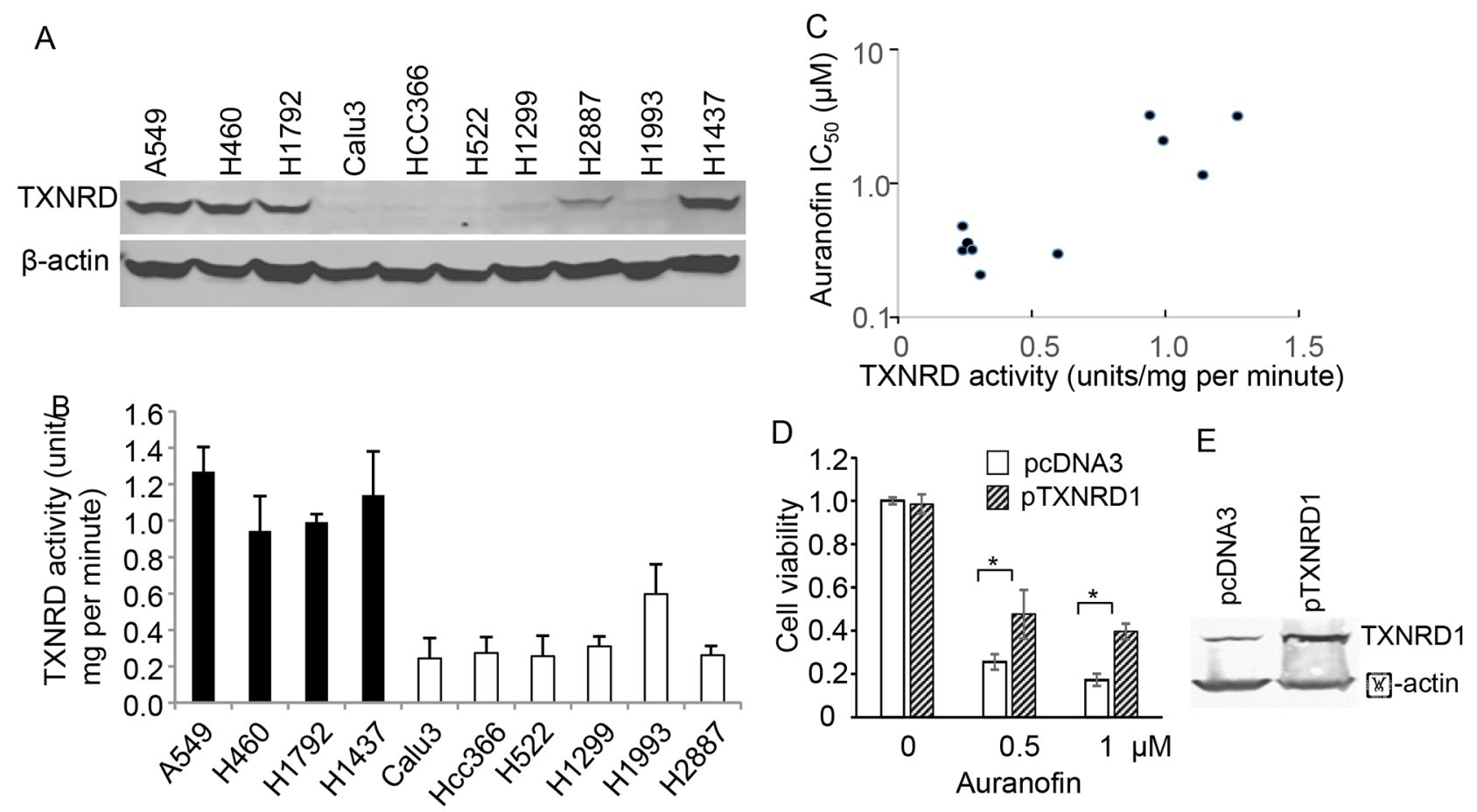

Figure 3. Association of TXNRD1 expression and auranofin's anticancer activity in NSCLC cells. A. Western blot analysis of TXNRD1 expression in NSCLC cell lines. $\beta$-actin is used as a loading control. B. TXNRD enzymatic activity levels in NSCLC cell lines. The values represent mean $+\mathrm{SD}$ of 3 triplicate assays. C. Correlations between TXNRD enzymatic activity and auranofin $\mathrm{IC}_{50} \mathrm{values}$ in 10 NSCLC cell lines. Results showed that the correlation was highly significant $(r=0.78, P=0.007)$. D. Effect of ectopic expression of TXNRD1 on auranofin's activity. Calu3 cells were transfected with pcDNA3 or pTXNRD1 for $24 \mathrm{~h}$ and then treated with auranofin for $72 \mathrm{~h}$. Cell viability was determined in a triplicate assay. The viability of control cells was set as $1 . *$ indicating $P<0.05$. E. Western blot for TXNRD1 expression in the cells described in (D). 
at 8 hours and were more profound at 24 hours. In contrast, expression of histone $\mathrm{H} 3$, demethylated histone $\mathrm{H} 3$, and pro-apoptotic proteins, such as Puma, Bax, and Bim, was dramatically induced at 24 hours, consistent with the cell death and apoptosis levels detected by annexin $\mathrm{V}$ and propidium iodide staining (see above). PhosphoCHEK1 and phospho-CHEK2 levels were increased at 3 and 8 hours, whereas SOD2 was increased at 24 hours, suggesting the presence of DNA damage and oxidative stress. Ingenuity Pathway Analysis (IPA) revealed that the $\mathrm{PI} 3 \mathrm{~K} / \mathrm{AKT} / \mathrm{mTOR}$ pathway was significantly inhibited at the time points of 8 and 24 hours $\left(P=7.5 \times 10^{-40}\right)$. The top upstream regulators identified by IPA are AKT, PTEN, TP53, doxorubicin and sirolimus (rapamycin) $(\mathrm{P} \leq 1.3 \times$ $\left.10^{-41}\right)$. This result strongly indicates that auranofin targets multiple key regulators in the PI3K/AKT/mTOR pathway and induced biological effects mimicking sirolimus. The significance of doxorubicin identified by IPA is not yet clear. However, identification of TP53 and doxorubicin in the pathway analysis may indicate that auranofin might induce DNA damage as well.

Because transient transfection of TXNRD1 expressing plasmid in Calu3 cells resulted in partial resistance to auranofin, we analyzed whether ectopic expression of TXNRD1 has any effects on auranofin-mediated inhibition of PI3K/AKT/mTOR pathway. For this purpose, Calu3 cells were transfected with TXNRD1 or a vector control plasmid expressing green fluorescent protein (GFP). Twenty-four hours after the transfection, cells were treated with $0.5 \mu \mathrm{M}$ auranofin. Cell lysates were harvested at 0,8 and $24 \mathrm{~h}$ after auranofin treatment. Calu3 cells treated with DMSO were used as controls. Phosphorylations of AKT (S473), 4EBP1 (S65) and mTOR (S2448) were determined by Western blot analysis. The results showed that ectopic expression of TXNRD1 partially reversed auranofin induced inhibition of phosphorylation of AKT, 4EBP1 and mTOR (Figure 5), indicating that TXNRD1 may participate in the regulation of PI3K/AKT/mTOR pathway and that high TXNRD1 levels can attenuate auranofin-induced inhibition of PI3K/ AKT/mTOR pathway.

\section{Auranofin has potent in vivo activity against lung cancer}

To determine whether auranofin had single-agent activity in vivo in NSCLC, we tested the activity of auranofin in a NSCLC xenograft tumor model derived

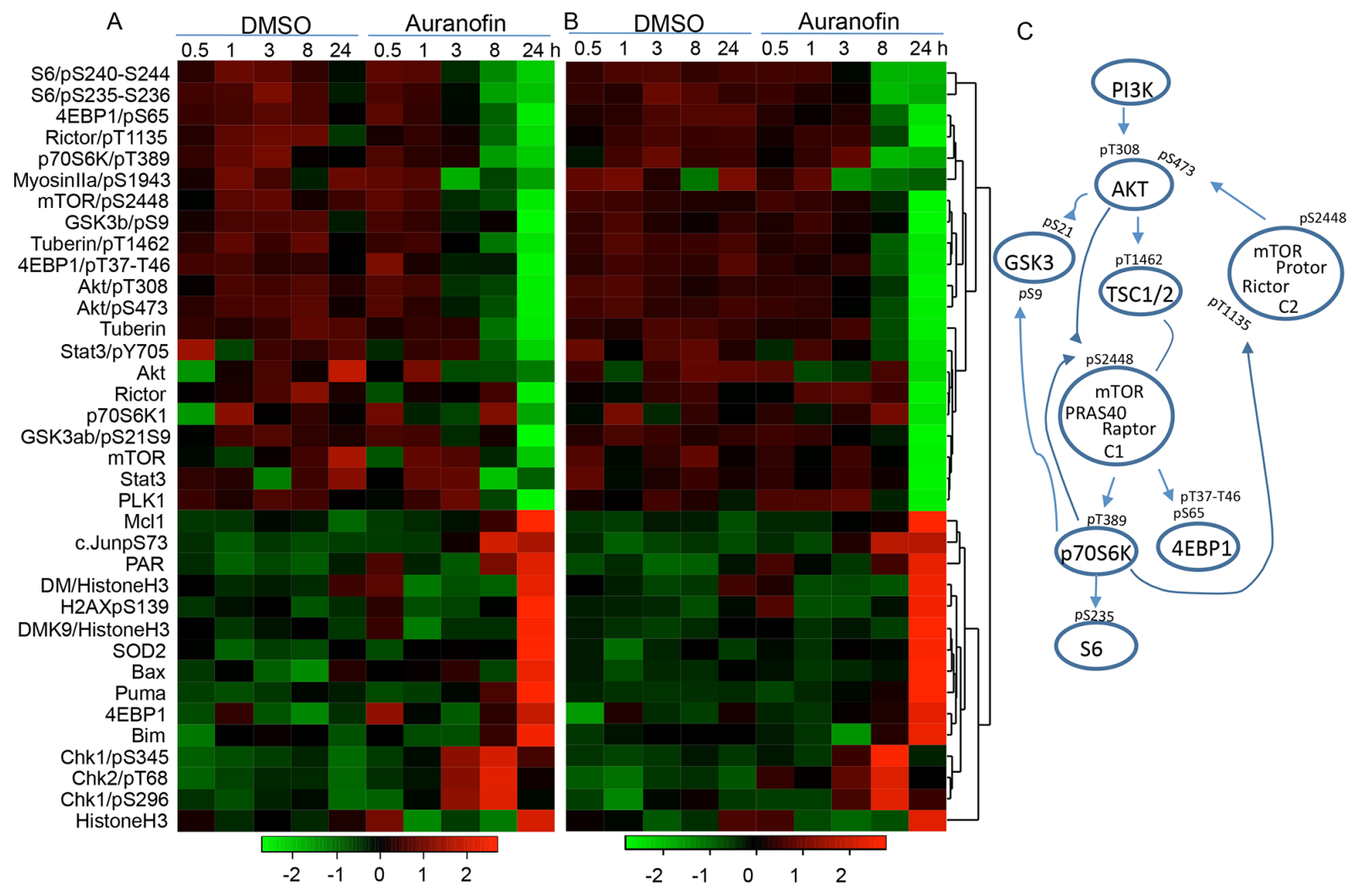

Figure 4. Proteomic analysis of auranofin-induced changes in proteins and protein phosphorylation in lung cancer cells. Calu3 and HCC366 cells were treated with $0.5 \mu \mathrm{M}$ auranofin for the indicated times. Cells treated with DMSO were used as controls. The cell lysates were subjected to RPPA analysis of 214 protein biomarkers. A and B. Heatmap of the top 36 proteins changed in Calu3 (A) and HCC366 (B) cells over time. C. Signaling transduction in the PI3K/AKT/mTOR pathway and phosphorylations inhibited by treatment with auranofin. 
from Calu3 cells. For this model, $3 \times 10^{6}$ Calu3 cells were inoculated subcutaneously into the dorsal flank of nude mice. After the tumors grew to $3-5 \mathrm{~mm}$ in diameter, the mice were grouped randomly into 2 groups $(n=6)$ and given daily intraperitoneal solvent (2\% DMSO, $8.5 \%$ ethanol, and $5 \%$ PEG-400) or auranofin $(10 \mathrm{mg} / \mathrm{kg})$ dissolved in the solvent. Tumor volume was monitored and calculated using the formula $a \times b^{2} \times 0.5$, where a represents the largest diameter and $b$ represents the smallest diameter. Results showed that treatment with auranofin resulted in significant growth suppression of Calu3 tumors in vivo (Figure 6). Treatment with auranofin led to $67 \%$ inhibition of tumor growth compared with control. No weight loss was detected in any of the treatment groups, suggesting that treatment with auranofin is effective for Calu3 tumors and is well tolerated.

\section{DISCUSSION}

Our results revealed that auranofin has in vitro and in vivo single agent activity against a subset of lung cancer cells. Auranofin alone can effectively inhibit multiple key nodes in PI3K/AKT/mTOR signaling pathways and elicit cytotoxic effects in NSCLC cells. Moreover, auranofin's anticancer activity might reversely correlate with TXNRD levels in cancer cells.

The use of auranofin for the treatment of various cancers has recently been explored [18-20], and auranofin is currently in clinical trials for the treatment of leukemia [21]. Previous mechanistic characterization has revealed that auranofin inhibits thioredoxin reductase (TXNRD) [19, 29], STAT3 [32], NF-кB [32], inflammasome receptor NLRP3 [33], proteasomal deubiquitinase [34], and selenoprotein synthesis [35]. Interestingly, NLRP3 activation mutations are present in $16 \%$ of lung adenocarcinomas and are significantly enriched for NF- $\mathrm{BB}$ activity [36]. Thus, most targets of auranofin are critically involved in cancer initiation, progression, and resistance to anticancer therapy. Nevertheless, using unbiased proteomic analysis, we found that treatment of lung cancer cells with auranofin inhibited phosphorylation of most key nodes in the $\mathrm{PI} 3 \mathrm{~K} / \mathrm{AKT} / \mathrm{mTOR}$ pathway, including S6, 4EBP1, Rictor, p70S6K, mTOR, TSC2, AKT, and GSK3, indicating that auranofin may target multiple sites in the $\mathrm{PI} 3 \mathrm{~K} / \mathrm{AKT} / \mathrm{mTOR}$ axis. Thus, inhibition of entire PI3K/ AKT/mTOR pathway by auranofin could be a novel mechanism of action in auranofin-mediated anti-lung cancer therapy.

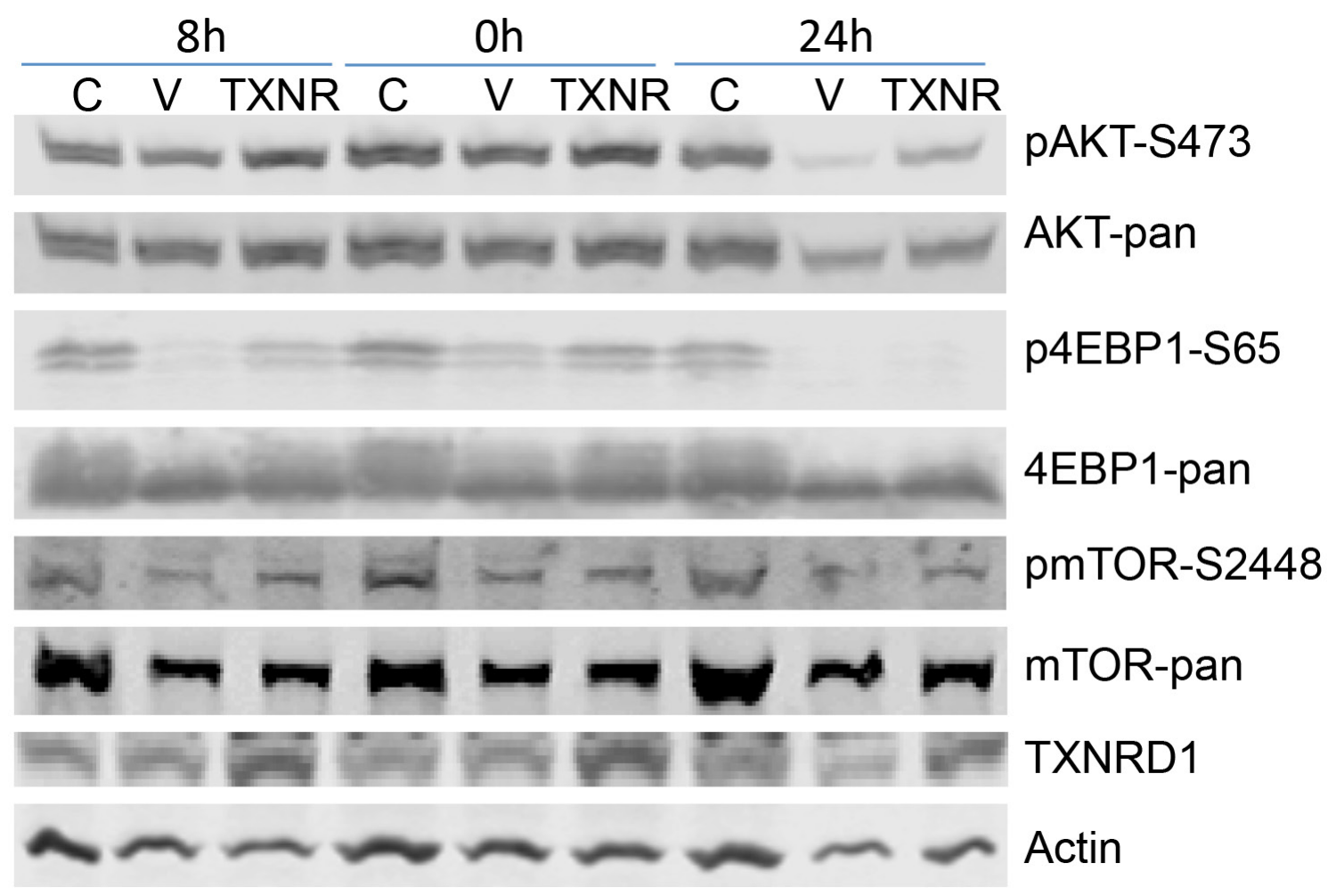

Figure 5. Effect of TXNRD1 expression in auranofin medicated inhibition of PI3K/AKT/mTOR pathway. Calu3 cells were transfected with TXNRD1 (TXNR) or GFP (V) expressing plasmids for $24 \mathrm{~h}$. Cells were then treated with $0.5 \mu \mathrm{M}$ auranofin for 0 , 8 and 24 h. Calu3 cells treated with DMSO (C) were used as controls. Pan- and phosphorylated proteins were detected by Western blot analysis. Treatment with auranofin resulted inhibition of phospho-AKT, -4EBP1, and - mTOR in vector transfected cells, which is partially reversed in TXNRD1 transfected cells. 
The $\mathrm{PI} 3 \mathrm{~K} / \mathrm{AKT} / \mathrm{mTOR}$ pathway is one of the major signaling pathways that regulate cell growth, proliferation, metabolism, and survival and is one of the most commonly deregulated pathways in cancer [37]. Inhibitors of the PI3K/AKT/mTOR pathway have been intensively investigated for anticancer therapy. In fact, the mTOR inhibitors everolimus and temsirolimus have been approved for the treatment of renal cancer [38] and breast cancer [39]. Nevertheless, inhibiting mTOR alone is known to activate PI3K/AKT via feedback loops [40], leading to attenuated therapeutic efficacy. Similarly, inhibiting PI3K or AKT alone resulted in feedback activation of upstream receptor tyrosine kinases [41, 42], highlighting the necessity of simultaneous targeting of multiple key nodes in cancer signaling networks for anticancer therapy to be effective. Consequently, several dual inhibitors of PI3K and mTOR, such as BEZ2359 (dactolisib) [43], PF04691502 [44], PKI-587 (gedatolisib) [45], DGC-0980 (apitolisib) [46], and GSK2126458 [47], are under extensive preclinical and clinical evaluations for anticancer therapy. As an FDAapproved drug with documented pharmacokinetic and safety profiles in humans, and having potent inhibitory effects in multiple sites of the PI3K/ATK/mTOR axis in human lung cancer cells, auranofin is likely for rapid clinical translation of its new application for lung cancer therapy.

Our results also suggested that endogenous levels of TXNRD1 expression in cancer cells are inversely associated with auranofin's activity, and causally associated with the resistance to auranofin in NSCLC cells. TXNRD/TXN is one of the major cellular enzyme systems executing an anti-oxidative stress function. Whether cells under high oxidative stress might be more vulnerable to auranofin, or whether levels of other redox regulatory systems in the cancer cells may affect auranofin's activity remains to be determined. Nevertheless, TXNRD/TXN is known to play important roles in cancer progression and anticancer therapy. TXN functions as an electron donor for ribonucleotide reductase which is critically involved in DNA synthesis [48]. The TXNRD/TXN system also catalyzes the reversible reduction of disulfides [49-51] or $S$-nitrosation $[52,53]$ of many cancer-associated transcriptional factors (p53, NF-kB, HIF1a), phosphatases (PTEN), kinases, apoptosis regulators (caspase-3, ASK1), and immune system modulators [54], thereby modulating the functions of the target proteins and regulating cellular redox homeostasis, DNA synthesis and repair, cell growth and survival, inflammatory response, and malignant progressions. Although little is known about the interactions between TXNRD/TXN and PI3K/AKT/ mTOR pathways, our results indicate that TXNRD/ TXN system may participate in the regulation of PI3K/ AKT/mTOR pathway and that high TXNRD1 levels can attenuate auranofin-induced PI3K/AKT/mTOR inhibition. The association between auranofin's anticancer activity and cellular TXNRD level indicates that TXNRD expression in cancer tissue might be a predictive biomarker for identifying responders of auranofin therapy, which may facilitate patient stratification in future design of clinical trials with auranofin.
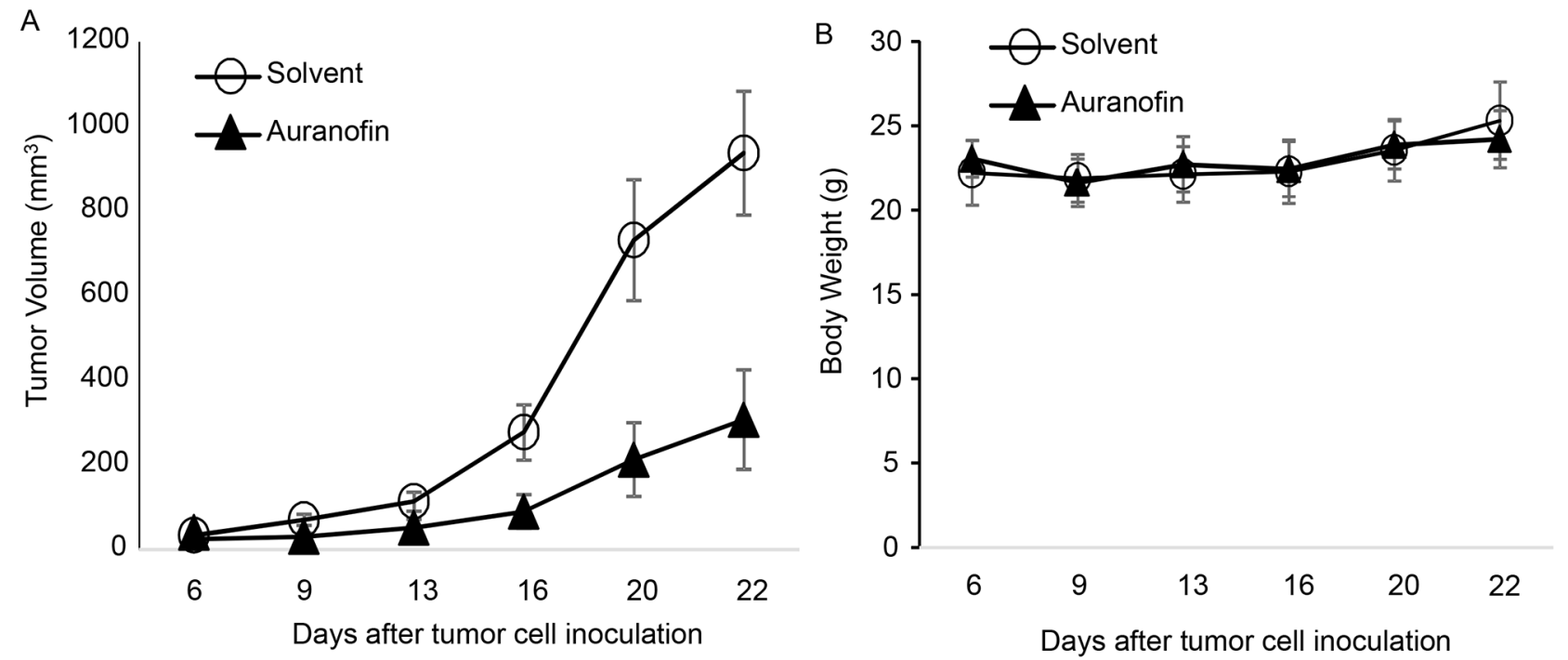

Figure 6. Auranofin-mediated in vivo activity in Calu3 xenograft tumors. A. Tumor Volume and B. Body Weight of animals treated with solvent or auranofin $(10 \mathrm{mg} / \mathrm{kg}$ per day). The values are mean \pm standard deviation $(\mathrm{n}=6$ per group). The tumor volume in auranofin treated group is significantly different from solvent group $(P=0.0002)$ when determined by ANOVA with repeated measurement module. 


\section{MATERIALS AND METHODS}

\section{Cell lines and cell culture}

Human non-small cell lung cancer (NSCLC) cell lines were maintained in our laboratories as previously described $[9,55]$. The authentication for each cell line was performed by DNA fingerprint analysis within 12 month. The cells were cultured in RPMI 1640 or highglucose Dulbecco modified Eagle medium supplemented with $10 \%$ fetal bovine serum, $100 \mu \mathrm{g} / \mathrm{mL}$ ampicillin, and $0.1 \mathrm{mg} / \mathrm{mL}$ streptomycin; they were maintained at $37^{\circ} \mathrm{C}$ in a humidified atmosphere containing $5 \% \mathrm{CO}_{2}$ and $95 \%$ air.

\section{Cell viability assay.}

Auranofin is obtained from Sigma-Aldrich Corporation. The inhibitory effects on cell growth were determined by using the sulforhodamine B assay, as described previously [56, 57]. Each experiment was performed in quadruplicate and repeated at least three times. The relative cell viability (\%) was calculated using the equation $\mathrm{OD}_{\mathrm{T}} / \mathrm{OD}_{\mathrm{C}} \times 100 \%\left(\right.$ where $\mathrm{OD}_{\mathrm{T}}$ represents the absorbance of the treatment group and $\mathrm{OD}_{\mathrm{C}}$ represents the absorbance of the control group). The median inhibitory concentration $\left(\mathrm{IC}_{50}\right)$ values were determined by using CurveExpert 1.3 software.

\section{Western blot analysis}

Western blot analysis was performed as described [57]. Antibody for pan- or phospho-MLKL, AKT, mTOR, and 4EBP1, and TXNRD1 were obtained from Abcam (Cambridge MA), Cell Signaling Technology (Danvers, MA) or R\&D Systems (Minneapolis, MN). Whole-cell lysates were prepared by washing the cells with phosphatebuffered saline solution (PBS) and subjecting them to lysis with RIPA buffer supplemented with the protease inhibitor cocktail. After the lysates were sonicated for $15 \mathrm{~s}$, the protein concentrations were quantified using the Bio-Rad protein assay kit. Equivalent amounts of each protein were loaded, separated by $10 \%$ or $12 \%$ sodium dodecyl sulfatepolyacrylamide gel electrophoresis, and then transferred to polyvinylidene fluoride membranes at $80 \mathrm{~V}$ for $2 \mathrm{~h}$. The membranes were blocked for $1 \mathrm{~h}$ with $5 \%$ nonfat dried milk in PBS buffer containing 0.1\% Tween-20 (PBST) and probed with diluted primary antibody at $4{ }^{\circ} \mathrm{C}$ overnight. The membranes were then washed three times in the PBST buffer and probed with infrared dye-labeled secondary antibodies. The immunoreactive bands were visualized with the Odyssey Imager (Li-COR Biosciences, Lincoln, NE).

\section{Biochemical and flow cytometric assays.}

Plasmid expressing TXNRD1 was obtained from GE Dharmacon Life Sciences (Lafayette, CO). Plasmid transfection was performed with Fugene 6 (Promega, Madison, WI), following manufactory's instruction. TXNRD1 activity assay was determined by using the TXNRD1 activity assay kit obtained from Sigma-Aldrich corporation, following the manufacturer's instructions as we previously described [11]. Auranofin-induced cytoxic effects was determined by fluorescence-activated cell sorting after staining with annexin V/propidium iodide.

\section{Reverse Phase Protein Array (RPPA) analysis.}

RPPA assay was performed at the Functional Proteomics Reverse Phase Protein Array Core facility at our institution as we previously described[30, 31]. Briefly, cells were treated with either auranofin or DMSO and harvested at the time points as indicated. Cells were then lysed in RPPA lysis buffer [1\% Triton X-100, 50 $\mathrm{mmol} / \mathrm{L}$ HEPES (pH 7.4), $150 \mathrm{mmol} / \mathrm{L} \mathrm{NaCl}, 1.5 \mathrm{mmol} / \mathrm{L}$ $\mathrm{MgCl}_{2}, 1 \mathrm{mmol} / \mathrm{L}$ EGTA, $100 \mathrm{mmol} / \mathrm{L} \mathrm{NaF}, 10 \mathrm{mmol} / \mathrm{L}$ $\mathrm{NaPPi}, 10 \%$ glycerol, $1 \mathrm{mmol} / \mathrm{L} \mathrm{Na}_{3} \mathrm{VO}_{4}, 1 \mathrm{mmol} / \mathrm{L}$ phenylmethylsulfonyl fluoride (PMSF), and aprotinin 10 $\mu \mathrm{g} / \mathrm{mL}]$ for $30 \mathrm{~min}$ with frequent vortexing on ice. The resultant solution was centrifuged for $15 \mathrm{~min}$ at 14,000 $\mathrm{rpm}$, the supernatant was collected, and the protein concentration was determined by routine (e.g., Bradford) assays and then adjusted to $1-1.5 \mathrm{mg} / \mathrm{ml}$ by lysis buffer. The samples were then submitted to the Functional Proteomics Reverse-Phase Protein Array Core facility at our institution for analysis with 197 validated antibodies specific for proteins or their phosphorylated sites that are involved in various signaling pathways. Signals from each dilution were fitted with the non-parametric model developed by the Department of Bioinformatics and Computational Biology at MD Anderson [58]. The protein concentrations of each set of slides were then normalized and corrected across samples by the linear expression values, using the median expression levels of all antibody experiments to calculate a loading correction factor for each sample, as previously described [30,31]. Heatmap is constructed by the R gplots program.

\section{Animal experiments}

Animal experiments were carried out in accordance with Guidelines for the Care and Use of Laboratory Animals (NIH publication number 85-23) and the institutional guidelines of M. D. Anderson Cancer Center. Subcutaneous tumors were established in 6- to 8-weekold female nude mice (Charles River Laboratories Inc., Wilmington, MD) by inoculation of $2 \times 10^{6}$ Calu 3 cells into the dorsal flank of each mouse. After the tumors grew to $3-5 \mathrm{~mm}$ in diameter, the mice were grouped randomly into two groups and treated with intraperitoneal administration of 1) auranofin (10 $\mathrm{mg} / \mathrm{kg} /$ day) and 2) solvent ( $2 \%$ DMSO, 10\% ethanol and 5\% polyethylene glycol 400). Tumor growth and animal body weight were monitored overtime. Tumor volumes were calculated by 
using the formula $\mathrm{a} \times \mathrm{b}^{2} \times 0.5$, where $\mathrm{a}$ and $\mathrm{b}$ represented the larger and smaller diameters, respectively. Mice werekilled when the tumors grew to $15 \mathrm{~mm}$ in diameter.

\section{Statistical analysis}

Each experiment or assay was performed at least two times, and representative examples are shown. Data are reported as mean \pm standard deviation (SD). Statistical significance of the differences between treated samples was determined by using the two-tailed Student $t$ test. Pearson correlation (assuming normality) were used to assess whether there were associations between auranofin's anticancer activity and TXNRD1 expressions. All statistical analyses were performed using IBM SPSS program (Version 22). Differences were considered statistically significant at $P<0.05$.

\section{ACKNOWLEDGMENTS}

This work was supported in part by the National Institutes of Health grants R01CA190628, Specialized Program of Research Excellence (SPORE) grant CA070907, and The University of Texas MD Anderson Cancer Center support grant CA-016672; the Translational and Analytical Chemistry Core, and the Flow Cytometry Core facilities of The University of Texas MD Anderson Cancer Center; and by endowed funds to The University of Texas MD Anderson Cancer Center, including the Lung Cancer Moon Shots Program, Stading Lung Cancer Research Fund, the Homer Flower Research Fund, and the Goldman Sachs Philanthropy Fund.

\section{CONFLICTS OF INTEREST}

The authors declare that they have no competing interests.

\section{REFERENCES}

1. GBD 2013 Mortality and Causes of Death Collaborators. Global, regional, and national age-sex specific all-cause and cause-specific mortality for 240 causes of death, 1990-2013: a systematic analysis for the Global Burden of Disease Study 2013. Lancet. 2015; 385:117-171.

2. Ferlay J, Soerjomataram I, Dikshit R, Eser S, Mathers C, Rebelo M, Parkin DM, Forman D, Bray F. Cancer incidence and mortality worldwide: sources, methods and major patterns in GLOBOCAN 2012. Int J Cancer. 2015; 136:E359-E386.

3. Edwards BK, Noone AM, Mariotto AB, Simard EP, Boscoe FP, Henley SJ, Jemal A, Cho H, Anderson RN, Kohler BA, Eheman CR, Ward EM. Annual Report to the Nation on the status of cancer, 1975-2010, featuring prevalence of comorbidity and impact on survival among persons with lung, colorectal, breast, or prostate cancer. Cancer. 2014; 120:1290-1314.

4. Moreno L, Pearson AD. How can attrition rates be reduced in cancer drug discovery? Expert Opin Drug Discov. 2013; $8: 363-368$

5. Ferri N, Siegl P, Corsini A, Herrmann J, Lerman A, Benghozi R. Drug attrition during pre-clinical and clinical development: understanding and managing drug-induced cardiotoxicity. Pharmacol Ther. 2013; 138:470-484.

6. Munos B. Lessons from 60 years of pharmaceutical innovation. Nat Rev Drug Discov. 2009; 8:959-968.

7. Singhal S, Mehta J, Desikan R, Ayers D, Roberson P, Eddlemon P, Munshi N, Anaissie E, Wilson C, Dhodapkar M, Zeddis J, Barlogie B. Antitumor activity of thalidomide in refractory multiple myeloma.[Erratum appears in N Engl J Med 2000 Feb 3;342:364]. N Engl J Med. 1999; 341:1565-1571.

8. Stachnik A, Yuen T, Iqbal J, Sgobba M, Gupta Y, Lu P, Colaianni G, Ji Y, Zhu LL, Kim SM, Li J, Liu P, Izadmehr $\mathrm{S}$, et al. Repurposing of bisphosphonates for the prevention and therapy of nonsmall cell lung and breast cancer. Proc Natl Acad Sci USA. 2014; 111:17995-18000.

9. Gao W, Wang M, Wang L, Lu H, Wu S, Dai B, Ou Z, Zhang L, Heymach JV, Gold KA, Minna J, Roth JA, Hofstetter WL, et al. Selective antitumor activity of ibrutinib in EGFR-mutant non-small cell lung cancer cells. J Natl Cancer Inst. 2014; 106:dju204-.

10. Jahchan NS, Dudley JT, Mazur PK, Flores N, Yang D, Palmerton A, Zmoos AF, Vaka D, Tran KQ, Zhou M, Krasinska K, Riess JW, Neal JW, et al. A drug repositioning approach identifies tricyclic antidepressants as inhibitors of small cell lung cancer and other neuroendocrine tumors. Cancer Discov. 2013; 3:1364-1377.

11. Dai B, Yoo SY, Bartholomeusz G, Graham RA, Majidi M, Yan S, Meng J, Ji L, Coombes K, Minna JD, Fang B, Roth JA. KEAP1-dependent synthetic lethality induced by AKT and TXNRD1 inhibitors in lung cancer. Cancer Res. 2013; 73:5532-5543.

12. Chaffman M, Brogden RN, Heel RC, Speight TM, Avery GS. Auranofin. A preliminary review of its pharmacological properties and therapeutic use in rheumatoid arthritis. Drugs. 1984; 27:378-424.

13. Marcolongo R, Mathieu A, Pala R, Giordano N, Fioravanti A, Panzarasa R. The efficacy and safety of auranofin in the treatment of juvenile rheumatoid arthritis. A long-term open study. Arthritis Rheumatism. 1988; 31:979-983.

14. Heuer MA, Pietrusko RG, Morris RW, Scheffler BJ. An analysis of worldwide safety experience with auranofin. J Rheumatol. 1985; 12:695-699.

15. Glennas A, Kvien TK, Andrup O, Clarke-Jenssen O, Karstensen B, Brodin U. Auranofin is safe and superior to placebo in elderly-onset rheumatoid arthritis. Br J Rheumatol. 1997; 36:870-877. 
16. Kean WF, Hart L, Buchanan WW. Auranofin. Br J Rheumatol. 1997; 36:560-572.

17. Debnath A, Parsonage D, Andrade RM, He C, Cobo ER, Hirata K, Chen S, Garcia-Rivera G, Orozco E, Martinez MB, Gunatilleke SS, Barrios AM, Arkin MR, et al. A highthroughput drug screen for Entamoeba histolytica identifies a new lead and target. Nat Med. 2012; 18:956-960.

18. Gandin V, Fernandes AP, Rigobello MP, Dani B, Sorrentino F, Tisato F, Bjornstedt M, Bindoli A, Sturaro A, Rella R, Marzano C. Cancer cell death induced by phosphine gold(I) compounds targeting thioredoxin reductase. Biochem Pharmacol. 2010; 79:90-101.

19. Schuh E, Pfluger C, Citta A, Folda A, Rigobello MP, Bindoli A, Casini A, Mohr F. Gold(I) carbene complexes causing thioredoxin 1 and thioredoxin 2 oxidation as potential anticancer agents. J Med Chem. 2012; 55:5518-5528.

20. Pessetto ZY, Weir SJ, Sethi G, Broward MA, Godwin AK. Drug repurposing for gastrointestinal stromal tumor. Mol Cancer Ther. 2013; 12:1299-1309.

21. Weir SJ, DeGennaro LJ, Austin CP. Repurposing approved and abandoned drugs for the treatment and prevention of cancer through public-private partnership. Cancer Res. 2012; 72:1055-1058.

22. Fiskus W, Saba N, Shen M, Ghias M, Liu J, Gupta SD, Chauhan L, Rao R, Gunewardena S, Schorno K, Austin CP, Maddocks K, Byrd J, et al. Auranofin induces lethal oxidative and endoplasmic reticulum stress and exerts potent preclinical activity against chronic lymphocytic leukemia. Cancer Res. 2014; 74:2520-2532.

23. Fries JF, Bloch D, Spitz P, Mitchell DM. Cancer in rheumatoid arthritis: a prospective long-term study of mortality. Am J Med. 1985; 78:56-59.

24. Lu H, Wang L, Gao W, Meng J, Dai B, Wu S, Minna J, Roth JA, Hofstetter WL, Swisher SG, Fang B. IGFBP2/ FAK pathway is causally associated with dasatinib resistance in non-small cell lung cancer cells. Mol Cancer Ther. 2013; 12:2864-2873.

25. Linkermann A, Green DR. Necroptosis. N Engl J Med. $2014 ; 370: 455-465$.

26. Wang H, Sun L, Su L, Rizo J, Liu L, Wang LF, Wang FS, Wang X. Mixed lineage kinase domain-like protein MLKL causes necrotic membrane disruption upon phosphorylation by RIP3. Mol Cell. 2014; 54:133-146.

27. Arner ES, Holmgren A. The thioredoxin system in cancer. Semin Cancer Biol. 2006; 16:420-426.

28. Arner ES. Focus on mammalian thioredoxin reductasesimportant selenoproteins with versatile functions. Biochim Biophys Acta. 2009; 1790:495-256.

29. Madeira JM, Gibson DL, Kean WF, Klegeris A. The biological activity of auranofin: implications for novel treatment of diseases. Inflammopharmacology. 2012; 20:297-306.

30. Wei X, Guo W, Wu S, Wang L, Lu Y, Xu B, Liu J, Fang B. Inhibiting JNK dephosphorylation and induction of apoptosis by novel anticancer agent NSC-741909 in cancer cells. J Biol Chem. 2009; 284:16948-16955.

31. He Y, Zhou Z, Hofstetter WL, Zhou Y, Hu W, Guo C, Wang L, Guo W, Pataer A, Correa AM, Lu Y, Wang J, Diao L, et al. Aberrant expression of proteins involved in signal transduction and DNA repair pathways in lung cancer and their association with clinical parameters. PLoS ONE. 2012; 7:e31087.

32. Nakaya A, Sagawa M, Muto A, Uchida H, Ikeda Y, Kizaki M. The gold compound auranofin induces apoptosis of human multiple myeloma cells through both down-regulation of STAT3 and inhibition of NF-kB activity. Leukemia Res. 2011; 35:243-249.

33. Isakov E, Weisman-Shomer P, Benhar M. Suppression of the pro-inflammatory NLRP3/interleukin-1beta pathway in macrophages by the thioredoxin reductase inhibitor auranofin. Biochim Biophys Acta. 2014; 1840: 3153-3161.

34. Liu N, Li X, Huang H, Zhao C, Liao S, Yang C, Liu S, Song W, Lu X, Lan X, Chen X, Yi S, Xu L, et al. Clinically used antirheumatic agent auranofin is a proteasomal deubiquitinase inhibitor and inhibits tumor growth. Oncotarget. 2014; 5:5453-5471. doi: 10.18632/oncotarget.2113.

35. Talbot S, Nelson R, Self WT. Arsenic trioxide and auranofin inhibit selenoprotein synthesis: implications for chemotherapy for acute promyelocytic leukaemia. Br J Pharmacol. 2008; 154:940-948.

36. Kim HS, Mendiratta S, Kim J, Pecot CV, Larsen JE, Zubovych I, Seo BY, Kim J, Eskiocak B, Chung H, McMillan E, Wu S, De BJ, et al. Systematic identification of molecular subtype-selective vulnerabilities in non-smallcell lung cancer. Cell. 2013; 155:552-566.

37. McCubrey JA, Steelman LS, Chappell WH, Abrams SL, Montalto G, Cervello M, Nicoletti F, Fagone P, Malaponte G, Mazzarino MC, Candido S, Libra M, Basecke J, et al. Mutations and deregulation of Ras/Raf/MEK/ERK and $\mathrm{PI} 3 \mathrm{~K} / \mathrm{PTEN} / \mathrm{Akt} / \mathrm{mTOR}$ cascades which alter therapy response. Oncotarget. 2012; 3:954-987. doi: 10.18632/ oncotarget.652.

38. Vogelzang NJ, Bhor M, Liu Z, Dhanda R, Hutson TE. Everolimus vs. temsirolimus for advanced renal cell carcinoma: use and use of resources in the US Oncology Network. Clin Genitourin Cancer. 2013; 11:115-120.

39. Baselga J, Campone M, Piccart M, Burris HA, III, Rugo HS, Sahmoud T, Noguchi S, Gnant M, Pritchard KI, Lebrun F, Beck JT, Ito Y, Yardley D, et al. Everolimus in postmenopausal hormone-receptor-positive advanced breast cancer. N Engl J Med. 2012; 366:520-529.

40. Carracedo A, Ma L, Teruya-Feldstein J, Rojo F, Salmena L, Alimonti A, Egia A, Sasaki AT, Thomas G, Kozma SC, Papa A, Nardella C, Cantley LC, et al. Inhibition of mTORC1 leads to MAPK pathway activation through a PI3K-dependent feedback loop in human cancer. J Clin Invest. 2008; 118:3065-3074. 
41. Chakrabarty A, Sanchez V, Kuba MG, Rinehart C, Arteaga CL. Feedback upregulation of HER3 (ErbB3) expression and activity attenuates antitumor effect of PI3K inhibitors. Proc Natl Acad Sci USA. 2012; 109:2718-2723.

42. Serra V, Scaltriti M, Prudkin L, Eichhorn PJ, Ibrahim YH, Chandarlapaty S, Markman B, Rodriguez O, Guzman M, Rodriguez S, Gili M, Russillo M, Parra JL, et al. PI3K inhibition results in enhanced HER signaling and acquired ERK dependency in HER2-overexpressing breast cancer. Oncogene. 2011; 30:2547-2557.

43. Maira SM, Stauffer F, Brueggen J, Furet P, Schnell C, Fritsch C, Brachmann S, Chene P, De PA, Schoemaker K, Fabbro D, Gabriel D, Simonen M, et al. Identification and characterization of NVP-BEZ235, a new orally available dual phosphatidylinositol 3-kinase/mammalian target of rapamycin inhibitor with potent in vivo antitumor activity. Mol Cancer Ther. 2008; 7:1851-1863.

44. Britten CD, Adjei AA, Millham R, Houk BE, Borzillo G, Pierce K, Wainberg ZA, Lorusso PM. Phase I study of PF-04691502, a small-molecule, oral, dual inhibitor of PI3K and mTOR, in patients with advanced cancer.[Erratum appears in Invest New Drugs. 2014 Jun; 32(3):575]. Invest New Drugs. 2014; 32:510-517.

45. Mallon R, Feldberg LR, Lucas J, Chaudhary I, Dehnhardt C, Santos ED, Chen Z, dos SO, Ayral-Kaloustian S, Venkatesan A, Hollander I. Antitumor efficacy of PKI-587, a highly potent dual PI3K/mTOR kinase inhibitor. Clini Cancer Res. 2011; 17:3193-3203.

46. Sutherlin DP, Bao L, Berry M, Castanedo G, Chuckowree I, Dotson J, Folks A, Friedman L, Goldsmith R, Gunzner J, Heffron T, Lesnick J, Lewis C, et al. Discovery of a potent, selective, and orally available class I phosphatidylinositol 3-kinase (PI3K)/mammalian target of rapamycin (mTOR) kinase inhibitor (GDC-0980) for the treatment of cancer. J Med Chem. 2011; 54:7579-7587.

47. Knight SD, Adams ND, Burgess JL, Chaudhari AM, Darcy MG, Donatelli CA, Luengo JI, Newlander KA, Parrish CA, Ridgers LH, Sarpong MA, Schmidt SJ, Van Aller GS, et al. Discovery of GSK2126458, a Highly Potent Inhibitor of PI3K and the Mammalian Target of Rapamycin. ACS Med Chem Lett. 2010; 1:39-43.

48. Sengupta R, Holmgren A. Thioredoxin and glutaredoxinmediated redox regulation of ribonucleotide reductase. World J Biolog Chem. 2014; 5:68-74.
49. Matthews JR, Wakasugi N, Virelizier JL, Yodoi J, Hay RT. Thioredoxin regulates the DNA binding activity of NF-kappa B by reduction of a disulphide bond involving cysteine 62. Nucleic Acids Res. 1992; 20:3821-3830.

50. Ueno M, Masutani H, Arai RJ, Yamauchi A, Hirota K, Sakai T, Inamoto T, Yamaoka Y, Yodoi J, Nikaido T. Thioredoxin-dependent redox regulation of p53-mediated p21 activation. J Biolog Chem. 1999; 274:35809-35815.

51. Huang LE, Arany Z, Livingston DM, Bunn HF. Activation of hypoxia-inducible transcription factor depends primarily upon redox-sensitive stabilization of its alpha subunit. J Biol Chem. 1996; 271:32253-32259.

52. Mitchell DA, Marletta MA. Thioredoxin catalyzes the S-nitrosation of the caspase-3 active site cysteine. Nat Chem Biol. 2005; 1:154-158.

53. Benhar M, Forrester MT, Hess DT, Stamler JS. Regulated protein denitrosylation by cytosolic and mitochondrial thioredoxins. Science. 2008; 320:1050-1054.

54. Castellani P, Angelini G, Delfino L, Matucci A, Rubartelli A. The thiol redox state of lymphoid organs is modified by immunization: role of different immune cell populations. Eur J Immunol. 2008; 38:2419-2425.

55. Liu X, Guo W, Wu S, Wang L, Wang J, Dai B, Kim ES, Heymach JV, Wang M, Girard L, Minna J, Roth JA, Swisher SG, et al. Antitumor activity of a novel STAT3 inhibitor and redox modulator in non-small cell lung cancer cells. Biochem Pharmacol. 2012; 83:1456-1464.

56. Pauwels B, Korst AE, de Pooter CM, Pattyn GG, Lambrechts HA, Baay MF, Lardon F, Vermorken JB. Comparison of the sulforhodamine B assay and the clonogenic assay for in vitro chemoradiation studies. Cancer Chemother Pharmacol. 2003; 51:221-226.

57. Huang X, Cao M, Wang L, Wu S, Liu X, Li H, Zhang H, Wang RY, Sun X, Wei C, Baggerly KA, Roth JA, Wang $M$, et al. Expression of sulfotransferase SULT1A1 in cancer cells predicts susceptibility to the novel anticancer agent NSC-743380. Oncotarget. 2015; 6:345-354. doi: 10.18632/ oncotarget.2814.

58. Hu J, He X, Baggerly KA, Coombes KR, Hennessy BT, Mills GB. Non-parametric quantification of protein lysate arrays. Bioinformatics. 2007; 23:1986-1994. 